\title{
Actualidad y vigencia del marxismo en el siglo XXI
}

\section{Carlos Montaño*}

Resumen. El presente artículo tiene el propósito de analizar la actualidad y la vigencia del marxismo en el siglo XXI. A partir de las tres fuentes de la obra de Marx, de acuerdo con Lenin, y de la caracterización lukacsiana de la ortodoxia, en la introducción se aborda el tema del llamado «marxismo ortodoxo», fiel al método marxiano y a sus fundamentos. En la primera sección se analizan los fundamentos marxianos y los del «marxismo ortodoxo» (la ontología, el método y la concepción de la historia). En la segunda sección se abordan los cambios (continuidades y rupturas) del capitalismo en movimiento y cómo estos han sido tratados por el «marxismo ortodoxo», mostrando el movimiento del pensamiento marxista en conjunción con el movimiento de la realidad. Finalmente, a modo de conclusión, se considera la actualidad y la vitalidad del marxismo en el siglo XXI.

Palabras clave: marxismo, actualidad del marxismo, marxismo en el siglo XXI, método, capitalismo.

* Profesor asociado e investigador de la Universidad Federal do Rio de Janeiro, Brasil.

Texto traducido y revisado a partir del artículo publicado en Brasil, en la Revista Praia Vermelha, 23(2), UFRJ, 2013. 


\section{CARLOS MONTAÑO}

\section{Actuality and validity of the Marxism in the 21st century}

Abstract. This article analyzes the relevance and validity of Marxism in the twenty-first century. The treatment of the theme is developed in the introduction -from the three sources of Marx's work (presented by Lenin) and Lukacsian characterization of orthodoxy - on the so-called «orthodox Marxism», faithful to the Marxist method and its fundaments. Thus, in item II, are analyzed such fundaments, Marxian and the «orthodox Marxism» (the ontology, method and conception of history). Then, in section III, we discuss the changes (continuities and ruptures) of capitalism in movement and how they have been treated by «orthodox Marxism», showing the movement of Marxist thought, accompanying the movement of reality. Finally, by way of conclusion, we consider the relevance and vitality of Marxism in the XXI century.

Keywords: Marxism, actuality of Marxism, Marxism in the XXI century, method, capitalism. 


\section{Introducción: las «fronteras» del marxismo ortodoxo}

Una versión bastante divulgada en las esferas académicas, las reuniones de diversos grupos políticos y las conversaciones en el bar es que «el marxismo, desactualizado, ya no explica más la nueva realidad contemporánea», que «sólo trata de la economía» o que «el marxismo murió con el fin de la Unión Soviética», y con ello «murió el proyecto revolucionario». No obstante, cabe preguntar: a quién puede interesarle la retirada del marxismo en el horizonte de análisis de la población?, ¿a quién puede interesarle que la clase trabajadora no cuente con el arsenal heurístico marxista para el análisis (crítico) de los fundamentos y los fenómenos de la realidad, que además oriente su acción política? Responder estas preguntas representa un punto fundamental para pensar la actualidad del marxismo en el siglo XXI, pues si realmente se tratara de una perspectiva superada, no sería tan resistida; en ese sentido, si es tan resistida es porque representa un peligro, una amenaza para las clases dominantes: el peligro de desvelar los fundamentos del modo de producción capitalista y de las contradicciones y luchas de clases.

Lenin contribuye con la respuesta al afirmar contundentemente que «en una sociedad fundada en la lucha de clases, ya no será posible una ciencia social «imparcial» (Lenin, 1983:71-72) y, complementando tal sentencia, Lukács sostiene que

después del surgimiento de la economía marxista, sería imposible ignorar la lucha de clases como un hecho fundamental del desarrollo social (...). Para huir de esta necesidad, surgió la sociología como ciencia autónoma (...). 


\section{CARLOS MONTAÑo}

Mientras que la sociología debe constituir una «ciencia normativa», sin contenido histórico y económico, la Historia debe limitarse a la explotación de la «unicidad» del decurso histórico, sin considerar las leyes de la vida social (Lukács, 2010:64).

La condenación del marxismo, en el mismo proceso en que surgen las «ciencias sociales particulares» en la senda de la razón positivista, busca simultáneamente el ocultamiento de las luchas de clases y la ilusión de un "conocimiento imparcial», "neutro", de un científico no comprometido, lo que en realidad esconde una «conciencia deformada» $\mathrm{y}$ «las intenciones perversas de la apología» burguesa (Marx, 1980:11).

Para tratar los fundamentos del marxismo y su vigencia, la primera tarea en la actualidad parece ser delimitar las «fronteras» del marxismo. ${ }^{1}$ Una tarea tan compleja como necesaria.

Compleja, porque la tradición marxista, en las antípodas de conformar un cuerpo cerrado de principios y dogmas, se ha constituido en un campo diverso, vasto y heterogéneo de pensamiento vivo, polémico y en constante construcción. No podría ser de otra forma, pues se trata de la perspectiva que busca constantemente afinar el pensamiento con la realidad dinámica y la producción de un conocimiento comprometido.

Necesaria, pues se atribuye al marxismo muchas cosas de las cuales no es responsable, por lo menos no el «marxismo ortodoxo». Al respecto, pueden considerarse dos aspectos. Por un lado, las perspectivas antimarxistas atribuyen al marxismo cuestiones que no reflejan su tradición

\footnotetext{
${ }^{1}$ Lukács, en una carta al entonces joven intelectual marxista brasileño Carlos Nelson Coutinho, recomendó: «Si tú quieres efectivamente estudiar el marxismo, debes estar muy atento sobre los autores que pueden ser considerados marxistas» (Pinassi y Lessa, 2002:144).
} 
teórico-política: que «no trata la subjetividad», que «no piensa el mundo contemporáneo», que «sólo trata la dimensión económica», que «rechaza y no dialoga con sus adversarios», que «no produce un saber científico, sino ideológico», etcétera. Al respecto, véanse, como ejemplo, las críticas de Boaventura de Souza Santos (1977), en De la mano de Alicia, quien ni siquiera trabaja con los principales autores de esta tradición; como en tantos otros casos, el «marxismo» que es criticado tiene muy poco que ver con la obra de Marx y con el rico pensamiento vivo de la dialéctica marxista. Por otro lado, en nombre del marxismo se ha promovido una «doctrina oficial» (el «marxismo-leninismo») y se ha cercenado el pensamiento crítico; se ha operado la violencia de Estado; se ha tomado el concepto de «vanguardia» como una especie de justificativa para el adoctrinamiento y subordinación de las masas, o incluso se han «controlado» movimientos sociales e instituciones públicas. De igual forma, al «activismo izquierdista» se le ha atribuido el carácter marxista (Lenin, 1977, no dudaría en llamarlo «enfermedad infantil del comunismo»). Se desarrolló un «marxismo cientificista» $\mathrm{o}$ «academicista» (sin compromiso), un «marxismo epistemologista» (equiparado a una «ciencia social particular»), un «marxismo historicista» (reducido al «materialismo histórico»y abandonando el «materialismo dialéctico») o un «marxismo estructuralista» (sin sujeto, sin historia, reducido al «materialismo dialéctico»y desconsiderando el «materialismo histórico»), $\mathrm{y}$, a veces, se ha procesado un excesivo «economicismo» claramente reduccionista y despolitizador. En nombre de un marxismo oficial se ha priorizado el oportunismo, subordinando tanto el conocimiento teórico crítico como las estrategias de la acción política a las tácticas y al interés inmediato. También, las categorías se han vaciado de contenido y 


\section{CARLOS MONTAÑo}

han sido empleadas como propias del marxismo; ${ }^{2}$ a veces se consideran igualmente válidas la crítica radical (que va a las raíces de la realidad) y la crítica moralista (subjetivista) en el análisis marxista, y se ha tratado de la misma forma el análisis científico (post festum) y las proyecciones (como tendencias para el futuro).

Ya desde los últimos años de la vida de Marx, en el contexto de la «I Internacional», han surgido tendencias «marxistas» que desvirtúan sus fundamentos. Aún más, en el periodo enmarcado por la «II Internacional», Lafargue, por ejemplo, en su libro El determinismo económico de Karl Marx, publicado en 1909, atribuía equivocadamente a Marx una visión economicista y perdía de vista la dimensión dialéctica en la concepción de la historia, o Kautsky, quien tendía a asimilar la realidad social a los fenómenos biológicos y reducía la teoría marxiana a una especie de «darwinismo social» (Konder, 1999:150), o incluso Bernstein, quien promovió «un abandono de la dialéctica, de la herencia hegeliana del marxismo y un retorno a Kant» (Konder, 2003:63). Pero las principales deformaciones de los fundamentos de la obra marxiana se sitúan en el escenario de la «III Internacional», a partir de la «autocracia estalinista» y de la (de)formación del «marxismo-leninismo» como una doctrina para orientar la acción política. Así, para Lukács, según lo atestigua en la «Carta sobre el estalinismo» (escrita en 1962), además de «un culto a la personalidad», bajo el estalinismo «las necesidades tácticas inmediatas subordinaron la elaboración teórica y paralizaron el pensamiento marxista, sometiéndolo a exigencias groseramente pragmáticas

2 Por ejemplo: la categoría clase social tratada como la diferencia entre pobres y ricos; la categoría trabajo equiparada a empleo; la identificación de la clase con pueblo, ciudadano, etcétera; los caminos metodológicos del análisis y la sintesis entendidos como inducción y deducción; la categoría totalidad identificada como el todo orgánico de Durkheim; la dialéctica como dialógica, etcétera. 
y oportunistas» (apud Netto, 1983:72-73; véase también Lukács, 2008:134; Lukács, en Pinassi y Lessa, 2002:126), que influyen en buena parte de la acción política y de la producción teórica afinada a esta «doctrina», incidiendo incluso, como observa Lukács en la Contribución al debate entre China y la Unión Soviética (1963), en el «maoísmo», considerado como «una derivación sectaria neoestalinista» (Netto, 1983:73).

Es por este tipo de cuestiones dichas/hechas en nombre del «marxismo» que Engels, en su carta a J. Bloch (en 1890), a propósito del excesivo economicismo, afirma que «no puedo eximir de esta crítica a muchos de los más recientes «marxistas`, pues también de este lado han surgido las basuras más asombrosas» (en Marx y Engels, 1987:381; véase también Engels, s/f), y Marx, de forma aún más contundente, comentó a su yerno, Paul Lafargue: «Ce qu'il y a de certain c'est que moi, je ne suis pas Marxiste» («De lo que tengo certeza es que yo no soy marxista») (Engels, 1882).

Evidentemente, muchas de esas cuestiones son producto de la existencia no de un marxismo, sino de varios marxismos (Wright, 1968:11; Burdeau, 1969:87; Hobsbawm, 1987:13-14; Netto, 1990:8-9; Fernández, 2009); sin embargo, al abordar la actualidad del marxismo en el siglo XXI nos orientaremos sólo en la consideración de lo que llamaremos, siguiendo a Lukács (1974), «marxismo ortodoxo».

Para que tal perspectiva teórico-metodológica no sea confundida sumariamente con la autoimagen de unos y la imagen atribuida por otros, algunas consideraciones precisan ser hechas para establecer, aunque sea de forma relativa y flexible, una frontera en el «marxismo ortodoxo»: una frontera teórico-filosófica y una frontera histórico-sistémica del marxismo ortodoxo (del marxismo fiel a los fundamentos de la obra de Marx). 


\section{CARLOS MONTAÑo}

\section{Las fronteras teórico-filosóficas del marxismo ortodoxo}

Sin pretender delimitar el marxismo como una corriente homogénea, única, definiendo lo que es y lo que no es «marxista», nos interesa aquí, en primer lugar, diferenciar la obra de Marx de la tradición marxista y, en segundo lugar, diferenciar el "marxismo ortodoxo» (fiel a los fundamentos de Marx) de otras corrientes marxistas. De esta forma, Francisco Fernández Buey, en su Marx (sin ismos), afirma que «no sólo se puede establecer una línea de separación (...) entre la obra de Marx y los marxismos posteriores, sino también se debe» (2009:229). Así, Lenin, como trataremos a continuación, va a contribuir con la determinación de los fundamentos de la obra de Marx, mientras que Lukács, a su vez, va a caracterizar al «marxismo ortodoxo».

En este sentido, para pensar la actualidad del marxismo, lo haremos en relación con el «marxismo ortodoxo». Para ello, presentaremos dos dimensiones para pensar sus fronteras teórico-filosóficas. Trataremos aquí, por lo tanto, los fundamentos de la obra de Marx y del «marxismo ortodoxo».

\section{Las tres fuentes de Marx}

En primer lugar, cabe presentar lo que constituyen los pilares fundantes del pensamiento marxiano, presentados, de forma diferente, por Lenin (1983) y por Kautsky (2002), como las «tres fuentes» del pensamiento de Marx. Ellas son, para Lenin, la filosofía alemana, la economia política inglesa y el socialismo francés (Lenin, 1983:72 y ss.); mientras que Kautsky las caracteriza como las síntesis del pensamiento alemán, el pensamiento inglés y el pensamiento francés (Kautsky, 2002:29 y ss.). 
Kautsky entiende que cada área del pensamiento (filosofía, economía y política) y cada nación (Alemania, Inglaterra y Francia) se han desarrollado unilateralmente, sin articular las diversas áreas. Para él, la gran contribución de Marx fue la realización de la sintesis de todas ellas, permitiendo aún su superación (2002:29). A pesar de la antelación del texto de Kautsky (publicado en 1908), tomaremos como base el artículo de Lenin (publicado en 1913), para quien la genialidad de Marx se basa en su capacidad de apropiarse críticamente de «todo cuanto la humanidad creó de mejor en el siglo XIX» (1983:72). Marx incorpora y supera críticamente lo mejor del pensamiento heredero del iluminismo y de la modernidad. Sintetizaremos las tres fuentes de la siguiente forma:

a) El método de conocimiento: materialista, histórico y dialéctico. El materialismo histórico-dialéctico constituye la primera fuente del pensamiento marxiano. Este fundamento se realiza a partir de la crítica de la filosofía alemana, particularmente en la incorporación y superación de la «dialéctica idealista» de Hegel y del «materialismo contemplativo» de Feuerbach. Marx incorpora la dialéctica hegeliana, pero superando su carácter idealista; para él, su «método dialéctico (...) difiere del método hegeliano», pues en Hegel, el proceso del pensamiento (idealista) es el creador de lo real, mientras que en Marx, lo ideal no es más que lo material transpuesto a la cabeza del ser humano y por ella interpretado, así, «en Hegel, la dialéctica está de cabeza para abajo. Es necesario ponerla de cabeza para arriba, a fin de descubrir la sustancia racional dentro de la envoltura mística» (Marx, 1980:16). También el autor incorpora el materialismo feuerbachiano, pero superando su condición contemplativa, al concebir la implicación del sujeto con la realidad, tornando la realidad no más «natural», sino histórica. Para Marx, «el defecto fundamental de todo materialismo anterior (...) está en que sólo 


\section{CARLOS MONTAÑO}

concibe el objeto, la realidad, el acto sensorial, bajo la forma de objeto o de percepción, y no como actividad sensorial humana, como práctica» (tesis I); por ende, si «los filósofos no hicieron más que interpretar el mundo», cabe ahora la tarea de «modificarlo» (tesis XI) (Marx, 1975:119-120). Marx funda así el «materialismo dialéctico» y el «materialismo histórico», sobre los cuales elabora su método.

b) El análisis concreto del modo de producción capitalista: fundamentos, categorías y fenómenos. Las teorías del valor-trabajo y de la plusvalía conforman la segunda fuente del pensamiento de Marx. Aquí Marx se apropia críticamente de las contribuciones de la economía politica inglesa, particularmente de Adam Smith y David Ricardo, fundando la crítica de la economía política, para tratar la realidad concreta del modo de producción capitalista. Los economistas políticos clásicos tienen el mérito monumental de haber concebido la riqueza, no como determinación divina, sino como producto del trabajo. Smith y Ricardo, así como Locke, al afirmar que la riqueza existente es producto del trabajo (y en esto contribuyen con una comprensión iluminista revolucionaria), fundan una nueva justificación y legitimidad para la propiedad privada: si la riqueza es resultado del trabajo, la pobreza será el resultado de menos trabajo o del consumo y gasto excesivo. Riqueza, pobreza y desigualdad ahora no son más una determinación divina o natural, sino el resultado del trabajo individual. Al incorporar la teoría del valor-trabajo, Marx la retira de su dimensión abstracta y la pone en el sistema social concreto, en el modo de producción capitalista. Entonces, la riqueza (y la pobreza) en el orden burgués es el resultado del trabajo, pero éste se realiza como trabajo asalariado, cuya fuerza de trabajo es vendida por el trabajador y comprada por el dueño de los medios de producción (el capitalista), fundando un especial proceso 
de producción de plusvalía y de explotación. La «teoría del valor-trabajo» (como abstracción ahistórica en los pensadores liberales) asume en Marx, con la «teoría de la plusvalía», concreción histórica con el análisis de la producción y explotación de la «plusvalía» en el modo de producción capitalista; es decir, como afirma Lenin, «donde los economistas burgueses veían relaciones entre objetos (intercambio entre mercancías), Marx descubrió relaciones entre hombres» (1983:75). La riqueza, en este particular sistema social, no es el resultado del trabajo propio, sino de la explotación del trabajo ajeno, de la plusvalía producida por uno (el trabajador) y explotada por otro (el capitalista).

c) La perspectiva de revolución, frente a las contradicciones y luchas de clases. El «socialismo científico» y la «doctrina de las luchas de clases» constituyen la tercera fuente del marxismo. Marx se apoya aquí en la crítica al socialismo utópico francés, especialmente de Proudhon, Owen, Fourier, Sant Simon. En estos autores, Marx encuentra lo que llama una «crítica romántica» al capitalismo, una crítica fundada en apreciaciones morales o nostálgicas, pero que (justamente por eso) no consiguen alcanzar la raíz, los fundamentos del orden burgués. Marx, con Engels, desarrolla así una crítica científica, radical, alcanzando los fundamentos del modo de producción capitalista, fundando el «socialismo científico». Pero un tal conocimiento de los fundamentos de una sociedad de clases, estructuralmente desigual, no concuerda con un intelectual neutro, imparcial, contemplador, sino involucrado, articulado y comprometido. Comprometido e involucrado con las luchas de las clases trabajadoras, buscando la transformación social, la superación del orden burgués, en la construcción de una sociedad verdaderamente emancipada: el socialismo, como camino para el comunismo. 


\section{CARlos Montaño}

Son estos los tres pilares, las tres fuentes del pensamiento marxiano, que lo distingue de la amplia, rica y plural tradición marxista. Podemos así afirmar que estos tres fundamentos de la obra de Marx constituyen la primera frontera. El conocimiento producido en discrepancia con por lo menos uno de estos tres pilares, podríamos decir que, aunque próximo, se sitúa fuera de las fronteras teórico-filosóficas y políticas de la obra de Marx.

\section{El marxismo ortodoxo}

Con estos fundamentos, columnas vertebrales del pensamiento marxiano, un segundo aspecto a considerar para delimitar tales «fronteras» es presentado por Lukács, a partir de su ponderación sobre «lo qué es el marxismo ortodoxo».

Primero, es necesario diferenciar la «ortodoxia» del «dogmatismo», generalmente confundidos o identificados. Por dogmatismo debemos entender la transformación del marxismo en una doctrina, en un conjunto de reglas, leyes y formulaciones que debe ser repetido acríticamente como una fe en un sistema cerrado, sin tensión interna, sin debate y sin movimiento — por ejemplo, la doctrina «marxista-leninista» establecida por la referida «autocracia estalinista». Contrariamente, la ortodoxia marxista, según Lukács: «No significa, pues, una adhesión sin crítica a los resultados de la investigación de Marx, no significa una 〈fe〉 en una u otra tesis, ni la exegesis de un libro «sagrado〉. Por el contrario, la ortodoxia en materia de marxismo se refiere exclusivamente al método» (Lukács, 1974:15).

El método, según Lukács, se particulariza, por un lado, por ser revolucionario (Lukács, 1974:16) y, por otro lado, por la «relación dialéctica del sujeto y del objeto en el proceso de la historia» (Lukács, 1974:17), también por partir 
de los hechos, de la realidad concreta (Lukács, 1974:19), tanto buscando superar su apariencia para alcanzar su esencia, como, al no concebirlo como hechos aislados, estableciendo las conexiones con la totalidad (Lukács, 1974:24).

Tenemos así la caracterización de lo que es, según Lukács, el fundamento de la ortodoxia marxista, esto es, la fidelidad (u ortodoxia) marxista no se confunde con «dogmatismo» — concibiéndolo como una «doctrina» cerrada—, sino que radica en la aplicación de su método de conocimiento: el materialismo histórico y dialéctico.

En el fondo, la determinación de las tres fuentes constitutivas del marxismo tratadas por Lenin y la caracterización lukacsiana de lo que es el marxismo ortodoxo representan la misma cuestión. En primer lugar, porque Lenin se refiere a los fundamentos del pensamiento de Marx. En segundo lugar, porque la fidelidad con Marx, la ortodoxia marxista, según el autor húngaro, radica en la fidelidad con el método de Marx, y este método consiste simultáneamente en el materialismo histórico y dialéctico (desarrollado a partir de la crítica a la filosofía alemana), en las categorías de análisis retiradas del propio modo de producción capitalista, como la teoría del valor-trabajo y la plusvalía (desarrolladas a partir de la crítica de la economía politica inglesa) y en la perspectiva de la revolución como perspectiva política frente a las luchas de clases (desarrollada a partir de la crítica del socialismo utópico francés). O sea, el método, como fundamento lukacsiano del marxismo ortodoxo, se configura por las mismas tres fuentes leninianas del pensamiento marxiano. El método marxista es el materialismo histórico y dialéctico, las categorías del modo de producción capitalista y la perspectiva de revolución. ¿El método son las tres fuentes!

Las tres fuentes constitutivas del pensamiento marxiano (presentadas por Lenin y de forma diferenciada por Kautsky) y el método como 


\section{CARLOS MONTAÑo}

fundamento de la ortodoxia marxista (según Lukács) nos permiten de alguna manera delimitar (aunque sea de forma flexible, y sin imaginar una tradición cerrada, homogénea, sino una viva y heterogénea) las «fronteras» del marxismo ortodoxo: el pensamiento no dialéctico (estructuralista, neokantiano, etcétera) o lejos de la perspectiva de totalidad; la no consideración de las categorías fundantes del modo de producción capitalista (clase, luchas de clases, plusvalía, etcétera) y de la teoría del valor-trabajo; la renuncia a la perspectiva de revolución sustentada en un posicionamiento de clase; por tanto, la ausencia de alguno de estos fundamentos, ciertamente, pone límites a la «ortodoxia marxista» de autores y actores. Es decir, cuando se retira del análisis uno de los tres fundamentos, de los tres pilares, de las tres fuentes y partes constitutivas de la obra de Marx (la dialéctica y el materialismo, la crítica de la economía política y la perspectiva de revolución), generalmente se deriva en una lectura, en una interpretación (y en una producción teórica y una acción política) reduccionista, recortada, no «ortodoxa» (estructuralista, economicista, academicista, politicista, etcétera). Veamos a continuación algunos ejemplos de esto.

Los estudios inspirados en la «crítica de la economía política», desarrollada por Marx, pero que han retirado de su horizonte los fundamentos de la dialéctica (la totalidad, la contradicción, el movimiento), a menudo derivan en un economicismo.

Aquellos inspirados en la dialéctica como método científico, que orientan análisis empíricos de la realidad, que sin basarse en la propia perspectiva de revolución (el lugar de los sujetos y de las luchas de clases en el proceso histórico, y el horizonte de la revolución), han fundado un fuerte academicismo en el marxismo. 
Los análisis de las estructuras del modo de producción capitalista, cimentados en el «materialismo dialéctico», que retiran el papel del sujeto, de las luchas de clases, y que han relegado el «materialismo histórico», frecuentemente han derivado en un estructuralismo.

En sentido inverso, el análisis del protagonismo de los sujetos, fundado en el «materialismo histórico», que desconsidera o subvalúa el peso de las estructuras y deja de lado el «materialismo dialéctico», muchas veces se ha orientado por un cierto voluntarismo o incluso una perspectiva historicista.

Otras veces el «marxismo» ha aparecido como sinónimo de «proyecto de revolución», sin embargo, sin los fundamentos teóricos de la dialéctica materialista y del análisis histórico inspirado en la «crítica de la economía política», tal postura ha derivado en un cierto activismo de izquierda o un pragmatismo político (desde un «sindicalismo de resultados» hasta las propuestas de moda de «acciones afirmativas»), claramente tacticista (donde la táctica, lo inmediato, subordina la estrategia y el análisis teórico crítico).

\section{Las fronteras histórico-sistémicas del marxismo}

Una vez delimitadas las fronteras teórico-filosóficas del marxismo ortodoxo, necesitamos considerar sus fronteras histórico-sistémicas. Es verdad que el método de Marx, el materialismo histórico y dialéctico, posee un cierto carácter universal. La dialéctica es un fundamento ontológico tanto de la realidad social (independientemente del sistema social específico) y de la naturaleza, como también del pensamiento que de ellas procura apropiarse; el carácter histórico de la realidad social es también un fundamento 


\section{CARlos Montaño}

que no se limita a un determinado modo de producción; el materialismo, que concibe la realidad (material) anterior e independiente del conocimiento, es de igual forma una determinación de carácter universal. Los caminos del análisis y de la síntesis tampoco se restringen a un proceso de conocimiento apenas circunscrito a un determinado sistema social. En este sentido, y a pesar de que Marx no haya desarrollado una propuesta metodológica con pretensiones universales (él sólo elaboró un método para sus investigaciones, véase Montaño, 2013:11-16), tal método de conocimiento que busca apropiarse fielmente del movimiento de la realidad, transponiéndola hacia el pensamiento, tiene de hecho un cierto carácter universal.

Sin embargo, el método marxiano, como veremos más adelante, se funda en un conocimiento comprometido sobre el modo de producción capitalista, se constituye así de la apropiación crítica de las categorías fundantes de este orden social (clase, explotación, trabajo asalariado, luchas de clase, alienación, etcétera) y del posicionamiento ideo-político: la perspectiva de revolución.

Al respecto, la validad del marxismo — como método y como fundamento teórico-filosófico e ideo-político- se restringe al modo de producción capitalista. Netto refuerza tal posicionamiento al afirmar que «la obra marxiana» es «esencialmente una teoría de la sociedad burguesa» (1990:21). Las categorías tratadas en el pensamiento marxista son extraídas del capitalismo y por lo tanto sólo fecundas para el análisis de la estructura y fenómenos del orden burgués: no hay «plusvalía» en el modo de producción feudal; no existe «trabajo asalariado» en las relaciones esclavistas; no hay «luchas de clases» en ciertas comunidades indígenas. Atribuir a otro orden social tales categorías sería una clara transposición de su validad histórica. 
Marx no se preocupó por un método y un cuerpo teórico común y general para cualquier formación social, sino apenas para comprender críticamente al modo de producción capitalista, en camino de su transformación. Es así que Lenin afirma: «Si Marx no nos dejó la Lógica (con L mayúscula), nos dejó la lógica de El capital» (2011:201).

Lo que tenemos, en la obra de Marx, es un pensamiento que procura apropiarse de la realidad concreta, y eso marca su carácter esencialmente ontológico (y no epistemológico): la estructura, la dinámica, los fenómenos propios del modo de producción capitalista. No se trata de una «epistemología», sino de una ontología del ser social.

Así, según Lenin, el método de Marx, lo que constituye «el alma viva, la esencia del marxismo», significa el «análisis concreto de una realidad concreta» (1989:284). En tal sentido, podemos caracterizar las fronteras histórico-sistémicas del marxismo en las propias fronteras del modo de producción capitalista.

\section{Marxismo: ontología, método e historia}

$\mathrm{Si}$, como fue expuesto, podemos establecer las «fronteras» del marxismo ortodoxo en su método, en las categorías de análisis sobre los fundamentos del modo de producción capitalista y en la perspectiva de revolución frente a las contradicciones y las luchas de clases, en esta sección retornaremos con más detalles a tales cuestiones. La actualidad y vigencia del marxismo en el siglo XXI radica en la vitalidad de estas cuestiones: de sus fundamentos ontológicos, de su concepción de historia y de su método de conocimiento — como el mejor camino para desvelar tanto los fundamentos estructurales y permanentes del modo de producción capitalista como 


\section{CARLOS MONTAÑo}

sus procesos dinámicos y las formas que asumen en la actualidad—, de las categorías de análisis que, a partir de la «crítica de la economía política», extrae de la propia realidad — la teoría del valor-trabajo, la explotación de plusvalía, las contradicciones y las luchas de clases, la alienación, así como el imperialismo, la crisis capitalista, etcétera-, y de su perspectiva anticapitalista y de transformación social — sin resignarse a un supuesto «capitalismo humano y verde», sin renunciar a la revolución.

\section{Los fundamentos ontológicos del ser social}

Afirma Lukács que, aunque raramente el marxismo haya sido entendido como una ontología, «el elemento filosóficamente decisivo en la acción de Marx constituye en haber esbozado los lineamientos de una ontología histórico-materialista» (2007:226). Y complementa: «La ontología marxiana se diferencia de la de Hegel por eliminar todo elemento lógico-deductivo, y en el plano de la evolución histórica, todo elemento teleológico» (Lukács, 2007:226). Sin embargo, si Marx «esboza» la ontología del ser social, será el viejo Lukács quien consolidará tal perspectiva. ¿En qué consiste la tan propalada «ontología del ser social»?

En primer lugar, explicitemos de qué se trata la «ontología». Para ello es necesario diferenciar la epistemología de la ontología como campos diferentes de la filosofía. Por un lado, la epistemología es la rama de la filosofía que estudia los fundamentos y métodos del conocimiento, con anterioridad e independencia del objeto de estudio concreto; la preocupación aquí es puramente gnoseológica (por ejemplo, la «razón pura» kantiana, como un conocimiento anterior a la experiencia, a la práctica, por lo tanto, a la relación 
sujeto-objeto). Por otro lado, la ontología es el campo de la filosofía que trata del ser, su naturaleza y sustancia, su estructura, fundamentos y movimiento, donde el proceso de conocimiento parte de la práctica (no necesariamente inmediata y personal), de la relación sujeto-objeto; por lo cual el conocimiento sólo es concebido como un proceso humano a partir y en función de un objeto real, material, concreto, y los fundamentos del método de conocimiento sólo pueden ser construidos a partir de los fundamentos del propio ser, de la propia realidad (por ejemplo, la ontología marxiana).

En segundo lugar, determinemos el sentido del término «ser social». Para ello, también es necesario distinguir las tres formas de seres o las tres esferas ontológicas que trata Lukács: el ser inorgánico, cuya determinación ontológica fundante remite al simple «tornarse otra cosa» (el agua en vapor, el carbón en energía, etcétera); el ser orgánico, cuya determinación ontológica fundante está en la «reproducción de la vida», en la «reposición de lo mismo»; y el ser social, cuya determinación ontológica fundante (momento predominante) remite a la «adaptación activa, con la modificación del ambiente», o sea al acto consciente de transformación de la naturaleza, de creación de lo nuevo (Lukács, 2007:227). Si cada ser tiene un fundamento ontológico distinto, cada uno preserva determinaciones del anterior (el ser orgánico del inorgánico y el ser social del orgánico) y promueve un «salto ontológico».

Por fin, consideremos los fundamentos de la «ontología del ser social». Para Lukács, la ontología de ser social reside en su capacidad de operar transformaciones conscientes en la naturaleza, de construir lo nuevo, de crear. Se trata de una actividad teleológica, o sea, de la pre-ideación de aquello que se desea crear. De esta forma, según Marx, «lo que distingue al peor arquitecto de la mejor abeja es que él figura en la mente su construcción 


\section{CARLOS MONTAÑO}

antes de transformarla en realidad», siendo que en este proceso «él no transforma apenas la materia sobre la cual opera, sino que él imprime a la materia el proyecto que tenía conscientemente en la mira» (1980, 1:202). Es decir,

el ser social, a diferencia de otros seres (orgánicos, naturales), transforma la naturaleza a partir de un plan preconcebido en su mente. En Marx, según Lukács, este proceso teleológico (consciente) de transformación de la naturaleza, de respuestas a necesidades, de construcción creativa de lo nuevo, se realiza a partir del trabajo (2007:229).

El trabajo, por lo tanto, en cuanto praxis social, representa la primera determinación ontológica del ser social. Así, como fundamento del ser social, el trabajo no puede confundirse ni con «empleo» (forma concreta del trabajo en el capitalismo), ni con el mero «dispendio de energía» (como la caza de los mamíferos predadores o la construcción de un nido por un pájaro, claras determinaciones de su propia naturaleza). El trabajo es el acto consciente, teleológico, de transformación de la naturaleza, a partir de una pre-ideación del sujeto, y representa la praxis que constituye el salto ontológico del ser orgánico para el ser social.

La praxis condensada en el trabajo, acción teleológica, consciente, exige una decisión entre alternativas (alternativas sobre el producto deseado, alternativas sobre las circunstancias a enfrentar y los caminos a seguir (Lukács, 2007:231). Por eso, Lukács considera que «el trabajo es un acto consciente, y por lo tanto presupone un conocimiento concreto, aunque jamás perfecto, de finalidades y medios determinados» (2007:233).

Y para Lukács, basándose en Marx, esto remite a la libertad. No la libertad concebida por los liberales (formal, «negativa»), ni la del sentido común (como naturaleza o desprendimiento), sino la concepción de libertad presente en la ontología del ser social, que remite justamente a la capacidad 
consciente de este ser de optar entre alternativas; la libertad apenas puede existir, por lo tanto, en el ser social. Así, para Marx,

el reino de la libertad comienza donde el trabajo deja de ser determinado por la necesidad y por la utilidad exteriormente impuestas (...). La libertad en este dominio sólo puede consistir en esto: el hombre social, los productores asociados regulan racionalmente el intercambio material con la naturaleza, lo controlan colectivamente (...). Pero este esfuerzo se colocará siempre en el reino de la necesidad. Más allá de él comienza el desarrollo de las fuerzas humanas como un fin en sí mismo, el reino genuino de la libertad, el cual sólo puede florecer teniendo por base el reino de la necesidad (1985, 3:942, cursivas nuestras).

Lukács aclara esto afirmando que «para Marx, el mundo de la economía (que él llama el «reino de la necesidad») será siempre, ineliminablemente, la base de aquella autocreación del género humano que él define como «reino de la libertad»; lo que lo lleva a concluir que «la praxis vinculada al «reino de la libertad`sólo pueda florecer «con base en el reino de la necesidad» (2008:112). Son las elecciones y las acciones conscientes lo que hace del ser social un ser efectivamente libre; o, en los términos de Lukács, «la libertad, así como su posibilidad, no es algo dado por la naturaleza, no es un don concedido a partir de lo alto, y ni siquiera una parte integrante - de origen misterioso - del ser humano. Es el producto de la propia actividad humana» (2007:241).

Es en el acto del trabajo, como praxis creadora, como acción teleológica, consciente, que el ser social se torna un ser libre, que realiza la libertad. Sólo puede ser realmente libre el ser que conscientemente puede optar 


\section{CARLOS MONTAÑo}

entre alternativas. Lo hará en condiciones históricamente determinadas, pero eliminando las barreras de la naturaleza que lo aprisionan, para transformarla, según su plan pre-idealizado, con la finalidad de responder a las necesidades.

\section{La concepción marxiana de historia}

Un segundo y fundamental aspecto a destacar en la presentación de aque1lo que diferencia el marxismo de las llamadas «ciencias sociales», o de las demás perspectivas teórico-metodológicas, en el análisis del modo de producción capitalista, remite a la clara comprensión de aquello que para Marx y para el marxismo ortodoxo es la historia, como ésta debe ser concebida y el lugar que ocupa en la elaboración teórica.

La historia es interpretada de diferentes formas, como «historiografía» o «evolución», «microhistoria», «historias de vida» o «subjetivas», en fin, cada perspectiva teórica irá a tratar la historia diferentemente, y ésta ocupará un lugar particular en su método de conocimiento.

Marx, ciertamente convencido de los límites de la comprensión historiográfica, o evolutiva (darwinista), ${ }^{3}$ para tratar los fundamentos del modo

${ }^{3}$ Tal como Lukács caracteriza la Historia en la razón burguesa, como limitada «a la exposición de la unicidad del decurso histórico, sin llevar en consideración las leyes de la vida social» (2010:64).

Marx ya había apuntado la necesidad de diferenciar la «historia idealista, tal como ha sido escrita» hasta entonces, de la «historia real», particularmente «las que se intitulan historias de la civilización, y que son todas historias de la religión y de los Estados». Y complementa que «a propósito, podemos referirnos también a los diferentes géneros de la historia escrita hasta el presente. La historia dicha objetiva. La subjetiva (moral, etcétera). La filosófica» (1977:227; 2011:62). 
de producción capitalista, funda una nueva concepción de historia. Según afirma en los Grundrisse y en la «Introducción a la Crítica de la Economía Política»: ${ }^{4}$

Sería por lo tanto imposible y equivocado clasificar las categorías económicas por el orden que fueron históricamente determinantes. Su orden es por el contrario determinado por las relaciones que entre ellas existen en la sociedad burguesa moderna, y es precisamente contrario a lo que parece ser su orden natural, o a lo que corresponde a su orden de sucesión en el decurso de la evolución histórica. No está en cuestión la relación [evolución] que se estableció históricamente entre las relaciones económicas en la sucesión de las diferentes formas de sociedad. Mucho menos su orden de sucesión «en la idea» (...). Se trata de su jerarquía en el cuadro de la moderna sociedad burguesa (1977:225-226; 2011:60).

Y aún más, Marx nos ilustra con un «ejemplo del lugar diferente que estas mismas categorías ocupan en diferentes instancias de la sociedad» $\mathrm{O}$ en diferentes sociedades (1977:226; 2011:61, cursivas nuestras):

El estado de pureza (determinación abstracta) en que aparecen en el mundo antiguo los pueblos comerciantes — fenicios, cartagineses — es determinado por la propia predominancia de los pueblos agricultores. El capital, en cuanto capital comercial o capital monetario, aparece precisamente bajo esta forma abstracta siempre que el capital no es aún el elemento dominante de las sociedades. Los lombardos y los judíos tienen la misma posición con relación a

${ }^{4}$ El mismo escrito aparece en ambos textos (Grundrisse e «Introducción» de 1857); optamos por la versión que nos pareció más clara. 


\section{CARLOS MONTAÑo}

las sociedades de la Edad Media que practican agricultura (1977:226; Marx, 2011:60).

Es decir, no es la evolución de las categorías (y fenómenos) a lo largo de los diferentes modos de producción (e independientemente de estos) lo que nos va a iluminar sobre los mismos; al contrario, es el lugar que ocupan esas categorías o esos fenómenos, su función social, en el modo de producción capitalista, que los determina concretamente, lo que nos permite la clara comprensión de los mismos.

El primer camino (de la evolución de los fenómenos a lo largo de las diversas sociedades), más común en los estudios «históricos», es claramente historiográfico, donde las categorías o los fenómenos son comprendidos en su evolución, en su desarrollo, como una concatenación de fases o etapas, pero sin las determinaciones históricas concretas dadas por los diferentes modos de producción. Así, consideradas las categorías y fenómenos independientemente de las formas concretas de sociedad en que existen, esta concepción de la «historia», evolucionista, historiográfica, se torna claramente ahistórica, en la medida en que aquellos son retirados y autonomizados de los fundamentos históricos de cada sociedad concreta, separados de la totalidad. Es como si se retirara la categoría o fenómeno de la realidad concreta, del modo de producción específico, y como si se considerara su evolución autónoma, independientemente de la propia Historia (general), apenas considerando su historia (específica), en una autoevolución. Como si pudiera estudiarse el «trabajo», el «sistema penal», el «sistema educacional», la «ayuda», la relación «ricos y pobres» y tantos otros fenómenos y categorías, siguiendo «su autoevolución» (endógena), en una relación lineal, unidimensional y unilateral de causa y efecto, atravesando (incólumes) las 
diferentes etapas de desarrollo social, los diferentes modos de producción, pero sin considerar su papel y el lugar que cada categoría y fenómeno asume en esas sociedades concretas, y cómo cada una de ellas determina y condiciona cada categoría y fenómeno en cuestión. ${ }^{5}$

Referente al segundo camino, aquel seguido por Marx, se concibe el análisis histórico partiendo del modo de producción específico, del contexto histórico-social concreto, para partir en el estudio de las categorías y de los fenómenos considerados en sus múltiples determinaciones. Por lo tanto, en este camino el punto de partida es la realidad concreta, el sistema social (general), el modo de producción, que contiene y determina todas las categorías, procesos y fenómenos que en su interior se desarrollan. Así, no es la evolución autónoma de cada categoría o fenómeno a lo largo de la historia, sino su inserción en la totalidad del sistema social (concreto) lo que constituye el punto de partida del análisis histórico para Marx: el «análisis concreto de la situación concreta», según afirma Lenin (1989:284).

Aquí, cada categoría (o fenómeno), si es desarticulada de la totalidad, del sistema social que la contiene y determina, de las relaciones con otras categorías, fenómenos y determinaciones, en fin, si es separada de la historia concreta, representa para Marx una abstracción:

La población es una abstracción si por ejemplo despreciamos las clases sociales que la componen. Por su turno, esas clases son una palabra hueca si ignoramos los elementos en que reposan, por ejemplo, el trabajo asalariado, el capital, etcétera. Éstos suponen el intercambio, la división del trabajo, los

${ }^{5}$ En el debate sobre la historia del Servicio Social tratamos esta concepción de historia como «endogenismo» (véase Montaño, 1998). 


\section{CARLOS MONTAÑO}

precios, etcétera. El capital, por ejemplo, sin el trabajo asalariado, sin el valor, sin el dinero, sin el precio, etcétera, no es nada (1997:218).

Si tomamos, como ejemplo, el «trabajo», en cuanto categoría simple, en cuanto abstracción, éste existió en todas las sociedades. Así, afirma Marx, en cuanto «categoría simple», el trabajo es una «expresión de relaciones en que lo concreto aún no desarrollado puede realizarse sin que aún haya dado origen a la relación o a la conexión más compleja» (1997:220). En este sentido (por ejemplo con la historiografía), podríamos seguir la evolución de la categoría de la forma «más simple a lo más complejo», correspondiendo «al proceso histórico real» (1997:220); podríamos pensar la evolución del trabajo a lo largo de la historia, pasando por todos los modos de producción. Contrariamente, para Marx es importante estudiar la categoría «trabajo» (y los fenómenos a ésta ligados) a partir del modo de producción concreto, del sistema social que lo determina, y en él se inserta, en las múltiples relaciones que establece con otras determinaciones y categorías. Entonces afirma el autor:

Este ejemplo del trabajo muestra con toda la evidencia que incluso las categorías más abstractas, aunque válidas - precisamente por causa de su naturaleza abstracta - para todas las épocas, no son, bajo la forma determinada de esta misma abstracción, menos el producto de condiciones históricas, y sólo se conservan plenamente válidas en estas condiciones [históricas] y en el marco de éstas (Marx, 1997:223, cursivas nuestras).

De esta manera, si el «trabajo», en cuando categoría abstracta, existe en todas las sociedades, justamente por eso esta categoría nada nos dice 
sobre el proceso de producción, las relaciones de producción y las formas específicas de distribución de riqueza en el capitalismo. A fin de entender los fundamentos de la sociedad capitalista es necesario comprender el «trabajo» como una categoría insertada y determinada por el modo de producción capitalista, como una categoría que así asume concreción histórica. El «trabajo» en sus múltiples determinaciones en la sociedad concreta, en el modo de producción capitalista, se enriquece así de sentido histórico. El «trabajo», comprendido en el modo de producción capitalista, deja su carácter de categoría abstracta y asume materialidad histórica: pasa a ser «trabajo asalariado», «trabajo productor de plusvalía», «trabajo subsumido al capital», «trabajo explotado», «trabajo alienado», «trabajo fundado en la mercantilización de la fuerza de trabajo», etcétera, y por lo tanto sólo válido para el «trabajo» en el modo de producción capitalista; ${ }^{6}$ asumiendo así, esta categoría (ahora concreta), fuerza heurística para explicar los fundamentos del orden social burgués.

El autor expone que son las condiciones que el trabajo asume en el modo de producción capitalista lo que determina sus fundamentos actuales, y no su evolución de las formas sociales anteriores: «Uno de los presupuestos del trabajo asalariado y una de las condiciones históricas del capital es el trabajo libre y el intercambio de trabajo libre por dinero [salario] (...). Otro presupuesto es la separación del trabajo libre de las condiciones objetivas de su efectivización — de los medios y del material de trabajo [de los medios de producción] (Marx, 1985a:65).

Por lo tanto, sólo puedo comprender el sentido y la función del trabajo en la actualidad si conozco los fundamentos del modo de producción

${ }^{6}$ Pero, alerta Marx, «nunca a la manera de los economistas que suprimen todas las diferencias históricas y ven en todas las formas de sociedad las de la sociedad burguesa» (1997:223). 


\section{CARLOS MONTAÑO}

capitalista (que lo funda y determina); de la misma forma, comprender tales fundamentos exige la clara caracterización del sentido del trabajo (libre, asalariado, mercantilizado, vendido y sometido al capital, productor de plusvalía, explotado, etcétera), que le confiera su peculiaridad este modo de producción específico. ¿Cómo podría comprender un determinado modo de producción sin caracterizar las formas concretas que asumen el trabajo y el proceso de producir?

Al respecto, en Marx no son las categorías más simples, abstractas, las que explican su desarrollo histórico, partiendo del escenario más antiguo hasta llegar a la sociedad moderna, sino al contrario, es en la sociedad contemporánea que las categorías asumen concreción, donde ellas se vuelven más complejas y expresan más determinaciones históricas. Para Marx, es lo más desarrollado (más complejo) que explica lo menos desarrollado (más simple): La anatomía del hombre es la clave de la anatomía del mono. En las especies animales inferiores sólo se pueden comprender los signos denunciadores de una nueva forma superior cuando esa forma superior ya es conocida. De la misma forma la economía burguesa nos da la clave de la economía antigua, etcétera (1997:223).

La concepción de la historia que pretende comprender de cada fase su desarrollo posterior —concepción historiográfica o evolutiva- presupone que las determinaciones de la fase ulterior ya están expresadas en el momento anterior, y que la exploración histórica envuelve el estudio de hechos concatenados en la secuencia con que ellos ocurrieron empíricamente (en una relación de causa y efecto). Marx advierte que no es posible comprender un periodo histórico (el modo de producción, los fenómenos y las categorías) a partir de su pasado. El punto de partida de la exploración histórica debe ser la fase más desarrollada, el presente, donde 
la realidad está más saturada de determinaciones, y éstas están más desarrolladas, más complejas, con más conexiones.

De esa manera, en su comprensión de la historia, el estudio de las categorías y fenómenos no debe partir de las formas más simples, pretendiendo una evolución hasta las formas más complejas (o de las más antiguas para las más recientes), como si los fenómenos en la fase superior explicaran su evolución posterior, como si el pasado explicara el presente, tal como es concebido en los estudios historiográficos.

Contrariamente, «eso que se llama desarrollo histórico, al fin y al cabo, se basa en el hecho de que la última forma considera las formas pasadas» (Marx, 1977:224, cursivas nuestras). Así, el punto de partida de la investigación histórica para el estudio de las categorías y los fenómenos concretos en la actual fase de desarrollo del modo de producción capitalista son las determinaciones actuales insertadas en el sistema social contemporáneo, enmarcadas por la totalidad social, en sus múltiples conexiones y relaciones con las demás determinaciones, consiguiendo captar el real sentido que la categoría o el fenómeno tiene en la sociedad concreta e iluminando los fundamentos de este sistema social.

La concepción marxiana de la historia y del conocimiento histórico de las categorías y los fenómenos, por lo tanto, exige constantemente partir de la realidad concreta, más desarrollada, actual, con la finalidad de entender la mayor riqueza de determinaciones en ésta. Se trata de un pensamiento vivo, y constantemente desafiado para comprender las nuevas determinaciones de la realidad contemporánea concreta. En tal sentido, resulta absolutamente infundada la afirmación de que el pensamiento marxista, al quedar congelado en el tiempo en las investigaciones de Marx del siglo XIX, no sería capaz de comprender el presente. 


\section{El método de Marx en la producción de conocimiento de la realidad}

Esta última cuestión repone a la consideración acerca del método de Marx, el materialismo histórico y dialéctico, en la medida en que se trata de un método que, buscando la transformación social, tiene por condición y exigencia la fiel reproducción intelectual del movimiento de la realidad.

1. Si la realidad histórica es dinámica, el método tiene que conseguir captar ese movimiento. Él debe estar constantemente buscando las nuevas determinaciones de la realidad.

2. Si la realidad se presenta de forma caótica, el método tiene que conseguir descifrar y aclarar los fundamentos de la realidad.

3. Si la realidad se muestra en su apariencia, el método tiene que alcanzar su esencia. Así, según Marx, «toda ciencia sería superflua si hubiera coincidencia inmediata entre la apariencia y la esencia de las cosas» (1985, 3:939).

Debemos, entonces, primero considerar cuáles son los fundamentos de la dialéctica de la realidad, para que entonces pensemos la dialéctica del conocimiento (o el método dialéctico).

El método que se funda en la dialéctica de la realidad. Marx pretende un método de conocimiento que consiga captar (lo más fielmente posible) el movimiento de la realidad. En este sentido la preocupación metodológica (gnoseológica), para Marx, es a posteriori, a partir y en función de su preocupación central sobre los fundamentos y el movimiento de su objeto, del ser social, del modo de producción capitalista. Por este motivo, el conocimiento en Marx es ontológico (y no epistemológico), por determinar los fundamentos de su método de conocimiento a partir de los fundamentos 
del propio «ser». Así, la dialéctica del conocimiento — la dialéctica como método gnoseológico, o el método dialéctico- es también la dialéctica de la propia realidad. La elaboración metodológica, para Marx (el método dialéctico de conocimiento), ya es un reflejo de la dialéctica del propio «ser», de la realidad social.

De esta forma, caracterizar la dialéctica del proceso de conocimiento, o el método dialéctico, por situarse en el campo de la ontología, presupone partir de la caracterización de la dialéctica de la realidad, del propio fundamento del ser social y particularmente del modo de producción capitalista.

Marx aprende con Hegel que la dialéctica de la realidad social (y de la naturaleza), de la historia, del ser social, significa, en primer lugar, que las cosas, la realidad, están en constante movimiento: el movimiento es constitutivo de la realidad. Otra condición de la dialéctica presente en la realidad es la contracción: todo proceso real, en constante movimiento, se opera a partir de la contradicción, de la afirmación y de la negación; la contradicción es el motor del movimiento, en un proceso de tesis, antitesis y sintesis. Aquí aparece el concepto de «superación dialéctica», siendo ésta la negación de lo que era, la conservación de algo esencial de la forma anterior, y la elevación a un nivel superior del nuevo «ser» (véase Konder, 2003:26). Finalmente, la dialéctica presente en la realidad muestra la articulación mutua de los fenómenos en una totalidad, en una relación entre lo singular, lo particular y lo universal.

Así es que Engels (1979:34 y ss.), al pensar la «dialéctica de la naturaleza», presenta tres leyes de la dialéctica: 1. La ley de la transformación de la cantidad en calidad (y viceversa), a partir de la cual cambios cuantitativos, que no alteran aún la esencia de los fenómenos, pueden llegar a un nivel 


\section{CARLOS MONTAÑo}

de transformación cualitativa. 2. La ley de la interpenetración de los contrarios, que remite a la relación existente entre todos los fenómenos de la realidad, en diferentes niveles de complejidad y universalidad, lo que exige su comprensión a partir de la totalidad y no de su aislamiento. 3. La ley de la negación de la negación, donde tanto la afirmación como la negación (constitutivas de la realidad) son superadas, concluyendo en una síntesis (la negación de la negación), en un proceso de tesis (afirmación, positividad), antítesis (negación, negatividad) y síntesis (negación de la negación).

De esta forma, el método dialéctico de conocimiento incorpora las determinaciones de la dialéctica de la realidad.

El método que parte de la realidad concreta, y que procura la fiel reproducción intelectual de la realidad, transpuesta para el pensamiento. El punto de partida del método (proceso) de conocimiento de Marx es la realidad, lo concreto. Es la práctica (social-histórica, no necesariamente individual e inmediata) que permite al sujeto apropiarse de la realidad concreta, en cuanto totalidad saturada de determinaciones; pero, dado su carácter complejo, como afirma Marx en su «Introducción de 1857», ésta se presenta de forma caótica, incomprensible (véase Marx, 1977:218-219).

Mediante el análisis, primer camino del pensamiento en el proceso de conocimiento, el sujeto desconstruye la totalidad caótica al separar sus partes, sus determinaciones, hasta alcanzar las formas más simples. Tales determinaciones simples, por ser simples y aisladas, sólo existen así apenas en el pensamiento, siendo por lo tanto abstracciones: la mercancía es una abstracción si es aislada del proceso de producción, del intercambio, de la explotación, etcétera; la población es una abstracción si está desvinculada de las clases que la componen, de sus contradicciones, etcétera; la moneda es una abstracción si no como medio universal de intercambio entre sujetos, etcétera. 
Pero, si lo concreto es una totalidad saturada de determinaciones, ¿cuáles particularidades, cuáles determinaciones, deben ser consideradas? Evidentemente aquí el investigador, el sujeto cognoscente, debe establecer priorizaciones necesarias para poder aprehender la realidad, separando lo esencial de lo accesorio; y este proceso es determinado por la teoría. No obstante, priorizar determinaciones con mayor poder explicativo no equivale a «determinismo económico», a absolutizar las determinaciones económicas; la riqueza del método dialéctico está en la perspectiva de totalidad, incluso cuando algunas determinaciones económico-políticas sean centrales para el conocimiento de los fundamentos de la producción y distribución de la riqueza social.

Una vez tratadas las particularidades en sus formas más simples y de forma aislada, cabe emprender «el camino de retorno», mediante la sintesis. En este proceso se relacionan las partes entre sí, se recompone la totalidad, hasta la reproducción de lo concreto (de la realidad) en el plano del pensamiento.

Así, la teoría es para Marx la representación intelectual del movimiento de la realidad (lo concreto pensado, lo concreto puesto en el pensamiento), y por lo tanto la teoría, el conocimiento teórico, representa una tendencia, que puede ser sometida a contratendencias históricas. Si Marx expone que el conocimiento debe partir de la realidad concreta, el marxismo ortodoxo, fundado en la fidelidad con su método, debe constantemente remitirse a la realidad. Se trata de un método que tiene como esencia, como fundamento y como necesidad, la constante referencia a la realidad sociohistórica. Constituye, por lo tanto, un conocimiento en constante construcción, en un movimiento que debe acompañar el propio movimiento de la realidad. Jamás tal perspectiva (el marxismo ortodoxo) 


\section{CARLOS MONTAÑo}

podría ser confundida como una doctrina, como un cuerpo teórico cerrado, pues su conocimiento producido se recrea con la propia recreación de la realidad en constante movimiento.

El método que se funda en el análisis de las categorías realmente existentes en la realidad. Si el método de Marx (y del marxismo ortodoxo) pretende apropiarse de la realidad para transponerla en el pensamiento, éste debe apropiarse de las categorías existentes en la realidad. Según Lukács, «las categorías no son elementos de una arquitectura jerárquica y sistemática, sino, al contrario, son en realidad formas de ser, determinaciones de la existencias, elementos estructurales de complejos relativamente totales, reales, dinámicos, cuyas inter-relaciones dinámicas dan lugar a complejos cada vez más amplios» (2012:297). Estas categorías, en la concepción marxiana, son del pensamiento porque son constitutivas (y extraídas) de la realidad.

Las categorías empleadas en el análisis de los hechos condicionan el tipo de conocimiento producido, el alcance de la comprensión sobre la realidad. Las categorías funcionan, para el científico social, como el microscopio o el reactivo para el biólogo. ${ }^{7}$ El tipo de categoría empleado para el conocimiento de la realidad social, como el tipo de microscopio o de reactivo en la investigación microorgánica, va a llevar a conocimientos diferentes. No es la misma cosa el conocimiento alcanzado sobre la realidad contemporánea a partir de unas u otras categorías de análisis: contradicción o disfunción, antinomias y harmonía; explotación o exclusión, o incluso opresión; clase social (fundada en el proceso de producción), o clases

${ }^{7}$ Como aclara Marx, en el Prefacio a la primera edición de El capital, «en el análisis de las formas económicas, no se puede utilizar ni microscopio ni reactivos químicos. La capacidad de abstracción [1legando a las determinaciones más simples] sustituye esos medios» (1980, 1:4). 
rica, media y pobre (o alta, media y baja, según el patrimonio o capacidad de acceso al mercado), o aún, ciudadanía o pueblo; luchas de clases o colaboración y articulación entre clases; imperialismo o globalización; sociedad civil o tercer sector; transformación o cambio, etcétera.

¿Por qué? Porque la contradicción trata del movimiento, de la transformación, pero la «harmonía» o la «disfunción» presupone un sistema perfectible pero no en transformación; porque la explotación hace referencia a la relación contradictoria entre las clases fundamentales en el proceso de producción del modo de producción capitalista (capital y trabajo). Su eliminación supone la superación del orden capitalista, en cuanto la «exclusión» remite a cualquier forma de desigualdad, y su resolución pasa por la «inclusión» (dentro del orden social vigente); porque la clase social (sustentada en el proceso de producción) remite a la relación contradictoria entre los dos sujetos fundamentales de la producción capitalista (dueños de fuerza de trabajo y dueños de medios de producción). Entretanto la noción de «clase» como ricos o pobres trata de una diferencia (de poder adquisitivo), pero no de una contradicción y, aún más, en cuanto la clase muestra la contradicción fundada en la división social del trabajo, el pueblo y la ciudadanía la esconden; porque las luchas de clases remiten a un proceso de conflicto (manifiesto o latente) que enfrenta las clases antagónicas, pero la colaboración o articulación induce al ocultamiento de tales antagonismos, de tales contradicciones, suponiendo la comunión de intereses; porque el imperialismo remite a un orden mundial marcado por el monopolismo, por la fusión del capital bancario e industrial, por el desarrollo desigual y combinado (países de centro y periferia, en una relación de dependencia), siendo que la llamada «globalización» esconde un proceso histórico, lo naturaliza y oculta el sujeto; porque la sociedad civil remite (incluso con tratamientos 


\section{CARLOS MONTAÑo}

diferentes) a una esfera de la totalidad social saturada de contradicciones y luchas, mientras que el llamado «tercer sector» supone su desarticulación de la totalidad y su homogenización y harmonía; porque la transformación significa la superación estructural del orden burgués, del modo de producción capitalista, pero los «cambios» remiten a alteraciones dentro del $-\mathrm{y}$ preservando el— sistema vigente.

Las categorías representan el arsenal heurístico, las herramientas de investigación, apuntando dónde y qué se va a observar de la realidad. Por lo tanto, el conocimiento alcanzado depende del tipo de categorías observadas. Pero estas categorías, más universales en el modo de producción capitalista, no ayudan a comprender apenas la estructura social más amplia. Su uso en el proceso de conocimiento de fenómenos más particulares - la cuestión del Estado, las políticas sociales, la desigualdad de género, la cuestión étnica, etcétera- o incluso singulares y locales —cuestiones en un grupo, en una familia, en un territorio determinados-, también es fundamental para el conocimiento crítico que consiga captar la esencia de esos fenómenos.

Y nuevamente aquí aparece la necesidad de priorizar, de establecer cuáles categorías (de mayor o menor universalidad o especificidad) serán prioritarias para el proceso cognitivo de fenómenos determinados, alcanzando su esencia y su conexión con otros fenómenos o con la realidad de mayor complejidad que lo contiene y determina.

Así, el método de Marx, fundamento del marxismo ortodoxo, no es apenas dialéctico, no se constituye apenas en los caminos de análisis y síntesis, sino que consiste también en el conocimiento a partir de las categorías (universales y particulares) extraidas de la propia realidad social. Pensar la realidad capitalista, en la actualidad, o sus fenómenos desarrollados en 
su interior, sin la consideración de las categorías contradicción, clase, plusvalía, explotación, imperialismo, etcétera, ciertamente producirá un conocimiento antagónico de aquel elaborado a partir del marxismo ortodoxo.

El lugar central de la "crítica radical» como arma en el proceso de conocimiento. Marx advierte que, el papel de la crítica es central en el proceso de conocimiento. Tal es así que, como ya observamos, los fundamentos de la obra marxiana se sustentan en la crítica de la economía política inglesa, en la crítica de la filosofía alemana y en la crítica del socialismo utópico francés. Aún más, en los textos de Marx la crítica siempre es el fundamento central; veamos los títulos de sus libros: Crítica de la filosofía del derecho de Hegel (1843); La Sagrada Familia o la Crítica de la crítica crítica contra Bruno Bauer y consortes (1845, con Engels); La ideología alemana. Crítica de la más reciente filosofía alemana en sus representantes Feuerbach, B. Bauer y Stirner, y del socialismo alemán en sus diferentes profetas (1845-1846, con Engels); Para la crítica de la economía política (1857); El capital. Crítica de la economía política (1867); Crítica al programa de Gotha (1875). No obstante si la crítica es central en el pensamiento marxiano, en el proceso de conocimiento de la realidad, en el tipo de envolvimiento de Marx con el orden social burgués, ¿de qué «crítica» estamos hablando?

Con frecuencia hay un uso del término «crítica» como rechazo: ser crítico a algo en este entendimiento significaría su rechazo, su descarte. Hay también una crítica restauradora: aquella que al rechazar lo «moderno», lo «nuevo», añora y propone la restauración de lo antiguo. Hay una crítica moralista: aquella que se funda en juicios de valores, en evaluaciones morales. Existe una crítica doctrinaria: cuando se rechaza todo lo que esté por fuera de cierta doctrina, de cierto dogma (como la religión). Podemos encontrar la crítica romántica o ingenua: cuando la crítica enfrenta un fenómeno o 


\section{CARLOS MONTAÑO}

discurso, pero sin conseguir captar sus fundamentos, apenas manifestando un descontento, a partir del sentido común, o deslizando para la crítica moral. Verificamos, como expresión de lo anterior, una forma de crítica puntual: centrada en procesos aislados, singulares, sin conexiones con las estructuras sociales, con los demás fenómenos, ciertamente tratando de las consecuencias y no de las causas, ignorando el peso de las estructuras y sin una perspectiva de totalidad.

Marx considera que la crítica no tiene cualquier relación con las anteriores: es una crítica radical. La crítica (radical) no puede ser rechazo, pues consiste en la incorporación y superación dialéctica. Ella jamás puede ser doctrinaria, o moralista, porque consiste en el conocimiento que aprehende, en el pensamiento, y fielmente, en el movimiento efectivo de la realidad. La crítica (radical) no tiene una orientación restauradora, ya que busca la transformación histórica orientada por el progreso y la emancipación humana. Y aún, la crítica marxista no puede ser romántica, ingenua, superficial o puntual; al sustentarse en la perspectiva de totalidad, debe captar los fundamentos de los procesos, la esencia de los fenómenos, llegando a la raíz de la realidad social. Se trata de una crítica radical.

Según nuestro autor, la crítica (radical) es una herramienta en el proceso de conocimiento, es un «arma», pues «la crítica no es la pasión de la cabeza, sino la cabeza de la pasión (...) un arma», sin que la crítica sea un «in en sí, sino apenas un medio» (Marx, 2005:147). Entonces, es necesario reconocer,

que el arma de la crítica no puede sustituir la crítica de las armas, que el poder material tiene que ser destruido por el poder material, pero la teoría se convierte en fuerza material cuando penetra en las masas. La teoría es capaz 
de penetrar las masas al demostrarse ad hominem, y se demuestra ad hominem luego que se torna radical. Ser radical es agarrar las cosas por la raiz. Pero para el hombre la raíz es el propio hombre (...) No basta que el pensamiento procure realizarse; la realidad debe igualmente compeler al pensamiento (Marx, 2005:151-152).

De esa manera, la teoría crítica (radical), el conocimiento crítico, por alcanzar la raíz de las cosas, cuando es apropiada por las masas, tiene, como un arma, fuerza material para la transformación social. El conocimiento materialista, histórico y dialéctico, es un conocimiento crítico radical, es un arma para las masas, para las clases trabajadoras, para la transformación social. He aquí la respuesta a nuestra primera pregunta, el motivo que funda tanto rechazo al método y a la teoría marxistas: se trata de una poderosa arma para la transformación social operada por las masas de trabajadores, cuando están en posesión de ésta, en camino de la emancipación humana.

El método que se funda en la relación sujeto-objeto y en la perspectiva de transformación social (revolución). Finalmente, se trata de un método de conocimiento sin pretensión de neutralidad $\mathrm{u}$ «objetividad», sino de un conocimiento articulado, comprometido, fundado en una relación sujeto-objeto.

Para Marx, el conocimiento no crea la realidad, porque ésta es anterior al conocimiento que de ella se tenga. Sin embargo, ese conocimiento se elabora en el envolvimiento e implicación del sujeto con la realidad social. Es un conocimiento, por lo tanto, saturado de valores, de posicionamientos éticos y políticos, de intereses. El conocimiento sobre la realidad social se produce a partir de los intereses y del envolvimiento del sujeto con la realidad... sepa el sujeto o no de ello. 


\section{CARLOS MONTAÑo}

En el proceso (de conocimiento), el sujeto, envuelto en la realidad, opera simultáneamente una transformación de la misma, que aún lo transforma a sí mismo. Al transformar la realidad, el sujeto se transforma a sí mismo, y al transformarse transforma la realidad. El conocimiento envuelve una relación de mutua implicación entre el sujeto y el objeto; implicancia ésta que se funda en los intereses, en los valores, en la ideología del sujeto. En el modo de producción capitalista tal implicancia, tal relación sujeto-objeto, envuelve la condición de clase frente a las contradicciones entre capital y trabajo, fundamento de la desigualdad en el orden burgués.

De esa forma, un cierto sentimiento se vuelve esencial en esta relación, en el proceso de conocimiento: la indignación. Marx explica que «la indignación es su [del conocimiento] modo esencial de sentimiento, y la denuncia su principal tarea» (2005:147). La indignación se torna, en la relación sujeto-objeto, en el proceso de conocimiento crítico, en el conocimiento comprometido, un sentimiento esencial; sin embargo, hoy tan dejado de lado. Hoy la naturalización de la realidad social histórica, la resignación y aceptación de las formas de desigualdad, de discriminación, de sumisión, de explotación, llevan a un vaciamiento de la capacidad de indignación de los sujetos: no nos indignamos más frente a la realidad... nos resignamos, naturalizamos esa realidad.

Además, Marx sostiene que el conocimiento crítico exige la indignación como sentimiento esencial, primario. Pero no basta la indignación. Como afirma, «la crítica no es la pasión de la cabeza, sino la cabeza de la pasión» (Marx, 2005:147). Es preciso, a partir del sentimiento de indignación, elaborar el conocimiento (científico) crítico, mediante la crítica radical, en el horizonte de la transformación social. 
En efecto, el pensamiento marxista se sustenta definitivamente en el posicionamiento (de los intereses) de la clase trabajadora, en su antagonismo con la burguesía, en un claro anticapitalismo, y por lo tanto en la perspectiva de revolución en busca de la emancipación humana. En palabras de Hobsbawm, «el marxismo (...) es un método para, al mismo tiempo, interpretar y cambiar el mundo» (1987:12). Es decir, es un conocimiento para alcanzar los fundamentos, la esencia del modo capitalista de producción. Es un conocimiento para la transformación social.

Tales fundamentos del marxismo ortodoxo, fiel al método de Marx, dada su ontología del ser social, dada su particular concepción de historia, dado su método de conocimiento materialista-histórico-dialéctico, y dada su perspectiva de revolución, constituyen los cimientos de un original análisis del modo capitalista de producción; fundan el «análisis concreto de la realidad concreta». En ese sentido, la teoría (el «punto de llegada» del proceso de conocimiento) es la reproducción del movimiento de la realidad transpuesta al pensamiento (siendo que la propia realidad social concreta constituye su «punto de partida»). Así, el punto de partida del análisis (concreto) de la historia (como realidad concreta) se funda en la crítica de la economía politica y procura aprehender las categorias fundantes del modo de producción capitalista: el «fetichismo» (de la mercancía); la «alienación» y la «reificación»; la categoría «trabajo» (tanto en el plano ontológico, como en su dimensión histórica en el modo de producción capitalista); el «capital» (como valorización del valor y como relación social); la «libertad» (fundada en la capacidad del ser social de elegir conscientemente entre alternativas), la cual es referencia para pensar la «emancipación humana»; la categoría «clase social» (fundada en el lugar que ocupan los sujetos en el proceso de producir valores), que establece relaciones sociales de «explotación» de «plusvalía» (como 


\section{CARLOS MONTAÑo}

el valor producido por el trabajador y apropiado por el capitalista en la relación salarial); finalmente, las «luchas de clases», que representan para Marx otra categoría central del modo de producción capitalista: el motor de la historia.

Sin duda, estas categorías son insuficientes para la exploración del sistema capitalista y de los fenómenos y procesos particulares, pero éstas son fundamentales para una comprensión crítica y radical (que procure alcanzar sus raíces), que consiga desvelar la esencia, la totalidad, de los fenómenos en movimiento. Tratar la realidad contemporánea, sea estructural (el modo de producción capitalista en general, por ejemplo), o sea en sus particularidades, en sus manifestaciones, en sus fenómenos específicos, sin partir, sin fundar los análisis en estas categorías, ciertamente distancia tal estudio de la perspectiva ortodoxa del marxismo. Jamás se llegará a las raíces de la realidad (en un conocimiento crítico, radical, comprometido), jamás se desvelará la esencia de los fenómenos en el orden burgués, si sus categorías fundantes no aparecen como instrumentos del análisis, si el arsenal heurístico empleado no cuenta con tales categorías. Si éstas no son suficientes, sin duda ellas son fundamentales... porque son fundantes.

\section{La dialéctica del capitalismo y la dialéctica del marxismo}

A partir de las consideraciones anteriores, es necesario en este momento tratar, aunque sea sumariamente, el movimiento del capitalismo (la dialéctica de la realidad, con sus continuidades y rupturas) y cómo éste ha sido acompañado por el marxismo ortodoxo en la búsqueda de captar, fielmente, tal movimiento, desde los análisis de Marx en el siglo XIX hasta la actualidad en el siglo XXI. 
El nuevo periodo histórico, post-Marx, será inicialmente enmarcado por dos guerras mundiales y por la Guerra Fría, con su impacto en la división militar, ideológica y económica del mundo entre las dos principales potencias: la capitalista, bajo la hegemonía estadounidense, y la socialista, bajo la influencia soviética, lo cual será considerado por Hobsbawm (1995) como la «era de los extremos» en el «breve siglo XX». Posteriormente, en los últimos tres decenios del siglo XX y en el pasaje al XXI, con la nueva fase de crisis capitalista, la extinción de la experiencia soviética y el fin de la Guerra Fría, y con la expansión hegemónica del neoliberalismo, profundas transformaciones en la estructura y en las dinámicas del capitalismo enmarcan el mundo contemporáneo.

Puede afirmarse que el capitalismo que Marx vivió y estudió, en su constante movimiento dialéctico, de conservación y rupturas, se ha desarrollado a lo largo del siglo XX hasta la actualidad, se ha vuelto compleja y se ha saturado de nuevas determinaciones. El pensamiento marxista (ortodoxo) se ha orientado al tratamiento de esta nueva realidad en movimiento. Algunos avances en los estudios para actualizar el análisis (ortodoxo) sobre la realidad en movimiento, en torno al modo de producción capitalista y sus fenómenos particulares, pueden ser sintetizados en varias de las siguientes obras.

En primer lugar, en el tránsito del siglo XIX al XX, con la formación de los monopolios, se abre una nueva fase del capitalismo: el «capitalismo monopolista», que sustituye la competencia intercapitalista por el control monopolista. Esta nueva «fase superior» del capitalismo constituirá lo que Lenin (1979) llamó «imperialismo» — fundado, a partir de una monumental centralización del capital, en la constitución del monopolio, en la fusión entre capital bancario e industrial que constituye el capital financiero, en 


\section{CARLOS MONTAÑo}

la exportación de capitales y no sólo de mercancías, y en el neocolonialismo. Rosa Luxemburgo (1985) analizará las nuevas condiciones históricas de la "acumulación de capital» y Ernest Mandel (1982) hará una caracterización diferente como «capitalismo tardío» — considerando el papel del monopolio, la economía armamentista, la tecnología y el desarrollo del Estado intervencionista. Sin embargo, el pensamiento marxista no paró en los estudios clásicos del imperialismo, también se ha debatido (y ha causado polémica) la actualidad (de continuidades y rupturas) del «nuevo imperialismo en el siglo XXI, en los textos de Borón (2002), Harvey (2004), Petras y Veltmeyer (2004) y Fontes (2010).

Al pensar el sistema mundo en el siglo XX, y particularmente el «desarrollo» del capitalismo monopolista (abordados por Barán, 1986, y Sweezy, 1986), estudiaron el caso de la periferia latinoamericana Mariátegui (1999) y Cueva (1990); y aún inspirados en la categoría de «desarrollo desigual y combinado» elaborada por Trotsky (2007:19 y ss.), el pensamiento marxista consideró el llamado «desarrollismo» como una nueva relación de dependencia entre países de centro y periferia, según los análisis de Theotonio dos Santos (1972), Ruy Mauro Marini (1977) y André Gunder Frank (1983), entre otros.

En este contexto, y resultado de las luchas de clases, el capitalismo en la segunda posguerra atribuyó nuevas funciones al Estado, el cual pasará a intervenir en la economía, en la regulación de las relaciones sociales y laborales, y en la acción social. Los estudios no marxistas lo caracterizan como «Estado de bienestar social» o «Welfare State»; por el contrario, autores como Antonio Gramsci (2000) — pensando el «Estado ampliado» constituido, a partir de la socialización de la política, por una «sociedad política» y una nueva «sociedad civil»— y Mandel (1982) — quien lo considera en 
la fase tardía del capital como «capitalista total ideal»— aprehendieron las nuevas determinaciones del Estado insertadas en la totalidad social y no como una entidad autónoma. El Estado, en el nuevo escenario de crisis capitalista, de fin de la Guerra Fría y de hegemonía neoliberal, sufre un proceso de contrarreforma monumental, que es tratado por diversos autores marxistas contemporáneos, como James O'Connor (1977) y Jean Lojkine (1977).

También, producto de la segunda revolución tecnológica (Mandel, 1982) y con la incorporación de nuevas formas organizativas (taylorista y fordista), se desarrolla un nuevo proceso de producción (en masa), que Harry Braverman (1987) tratará como una forma de «degradación del trabajo», vinculado a la gerencia, a la mecanización, al monopolismo y a la diversificación de la clase trabajadora. Sin embargo, a partir de la tercera revolución tecnológica y del nuevo contexto de crisis capitalista, hay una profunda reestructuración productiva que se inicia en los países occidentales en las décadas de 1980 y 1990, considerada por diversos estudiosos marxistas, por ejemplo, István Mészáros (2002), David Harvey (1993) y Ricardo Antunes (1999).

Tema particularmente neurálgico en el desarrollo capitalista contemporáneo es la irrupción, en el pasaje entre los 1960 y los 1970, de una nueva fase de crisis capitalista, poniendo fin al «régimen de acumulación fordista-keynesiano» (según la caracterización de Harvey, 1993). Sustentado en los fundamentos marxianos sobre la crisis capitalista, y siguiendo los desarrollos de Kondratiev, la actual fase de crisis es tratada de manera diferente por Mandel (1980; 1982) y Giovanni Arrighi (1996), ambos enfatizan su carácter cíclico, y por Mészáros (2002; 2009), quien destaca su carácter estructural y acumulativo. 


\section{CARLOS MONTAÑo}

A partir de esta crisis, el capital, como forma de preservar las elevadas tasas de lucro, promueve una fuga de la actividad productivo-comercial para la inversión financiera — sea en el «capital portador de interés», sea en el «capital ficticio»—, en lo que François Chesnais (1996) llama de «mundialización del capital», dando densidad histórica y sujeto a un proceso tratado como «globalización».

Este hecho pone a la fracción financiera del capital en el comando hegemónico del proceso de reestructuración capitalista, el llamado neoliberalismo, como el proyecto que, fundado en los postulados de Hayek, orientará el conjunto de «reformas» para, frente a la crisis, sustentar las superganancias del gran capital. Diversos trabajos tratan de este proceso, entre ellos destacan los de Harvey (2005) y Petras (1999).

Incluso, los análisis marxistas que abordan el capitalismo contemporáneo se orientan a cuestiones como la democracia (Domenico Losurdo, 2004; Ellen Wood, 2006), los diversos movimientos sociales (James Petras y Henry Veltmeyer, 2005; Samir Amin y François Houtart, 2003), el sujeto revolucionario, las luchas de clases, la cultura, la ideología, la pobreza, la vida cotidiana, etcétera.

Como se ve, en estas breves reflexiones, el marxismo ortodoxo ha efectivamente acompañado la reflexión sobre las novedades del capitalismo en movimiento. El tratamiento de las novedades, no obstante, no excluye la constatación de sus continuidades (en los fundamentos y ciertas dinámicas); se trata de un movimiento dialéctico de continuidades y rupturas. 


\section{Algunas consideraciones finales: la vigencia del marxismo en el siglo XXI}

Llegamos, en el final de este breve texto, al momento de reflexionar sobre la actualidad y la vigencia del marxismo en el siglo XXI; reflexión que expresa nuestro propósito en este artículo. Este ha sido el objetivo de varios marxistas, como Leandro Konder (1992) — aún bajo el impacto de la extinción del bloque soviético, en su texto El futuro de la filosofía de la praxis. El pensamiento de Marx en el siglo XXI-, Perry Anderson (1985) —una refutación en su libro La crisis de la crisis del marxismo-, Atilio Borón (2007) —en la compilación La teoria marxista hoy. Problemas y perspectivas - Francisco Teixeira y Celso Frederico (2008) - en el libro Marx en el siglo XXI-, Daniel Bensaïd (2011) —en el texto Marx ha vuelto-, entre tantos otros.

Nuestra hipótesis de trabajo, para pensar la actualidad y vigencia del marxismo, puede ser presentada de la siguiente forma:

1. El marxismo representa una tradición viva, rica, heterogénea y en constante desarrollo y debate interno, pero existen «varios marxismos» y corrientes diversas. En ese sentido, nos centramos aquí en los fundamentos de la obra de Marx — sus «tres fuentes», expuestas por Lenin — y en lo que, a partir de Lukács, tratamos como «marxismo ortodoxo» —las corrientes y autores fieles al método de Marx (que como ya apuntamos se funda en las propias fuentes de Marx). Al tratar de la actualidad y vigencia del marxismo en el siglo XXI lo hacemos en relación con el "marxismo ortodoxo».

2. A pesar de la existencia de tendencias dogmáticas (por ejemplo, la «doctrina marxista-leninista» promovida por el estalinismo, o el «maoísmo») y de corrientes reduccionistas (como el «economicismo», el «tacticismo», el 


\section{CARLOS MONTAÑo}

«estructuralismo», el «academicismo», el «historicismo», el «politicismo», etcétera), el marxismo siempre mantuvo un pensamiento vivo, crítico, fecundo, para pensar la realidad en constante movimiento, en camino de su transformación, buscando la emancipación humana. El diversificado campo del «marxismo ortodoxo» promovió un constante movimiento de exploración crítica y radical de la realidad en movimiento, actualizando constantemente el conocimiento de la misma.

3. Siendo el «marxismo ortodoxo» una perspectiva centrada en la fidelidad con el método de Marx y ya que este método ha sido constituido por la dialéctica materialista, por las categorías fundantes del modo de producción capitalista, tratadas a partir de la crítica de la economía política, y por la perspectiva de revolución, la actualidad y vigencia del «marxismo ortodoxo" radica en su capacidad de apropiarse (en el pensamiento) de la realidad concreta en movimiento, de la realidad actual, del capitalismo contemporáneo.

El desarrollo del capitalismo, del siglo XIX hasta el siglo XXI, el capitalismo en movimiento, representa un constante proceso de superación dialéctica; o sea, ni queda preso en la mera conservación de aquello que existía en el siglo XIX (tesis), ni representa la mera negación (antítesis), como si se tratara de otro orden social (por ejemplo, los profetas posmodernos, posindustrialistas, del «fin del trabajo», etcétera), sino que significa un movimiento de conservación y rupturas (síntesis).

$\mathrm{Si}$, como ya fue señalado, la concepción de la historia en Marx sostiene que lo más desarrollado explica lo de menor desarrollo, por presentar más y más complejas determinaciones, el propio Marx afirmaría enfáticamente que la sociedad contemporánea no podría ser explicada a partir de la mera repetición de las teorías producidas en el capitalismo del siglo XIX. 
Siguiendo el propio método de Marx, es preciso partir del presente, de la realidad concreta.

Es en este sentido que Lukács, según afirma Netto (1983:74), ha reiterado que los «nuevos fenómenos no pueden ser resueltos [meramente] con el apelo a Marx y Lenin», ya que si «los clásicos — Marx, Engels y Lenin— son necesarios», ciertamente ellos son «insuficientes»; su obra es insuficiente, porque es incompleta, para tratar los nuevos fenómenos actuales. Así, Mészáros trató, en su monumental obra de actualización teórica, Más allá del capital, la incompletud de la obra de Marx, del «proyecto inacabado de Marx» (Mészáros, 2002:517 y ss.). Netto comenta:

Está más o menos claro que la obra de Marx es inacabada. Pero un estudioso del marxismo, Maximilian Ribbel, escribió en 1968 un texto donde sostiene que la obra de Marx es inacabable. Si desde el punto de vista teórico la obra de Marx es la reproducción ideal del movimiento del capital en el capitalismo, es evidente que esa obra sólo se concluye cuando este movimiento del objeto real se agote. Cuando murió, en 1971, Lukács dijo que era necesario [escribir] otro El capital para el siglo XXI. El objeto que Marx estudió pasó por modificaciones sustantivas y aún está [en proceso de cambios]. De ahí que Marx es necesario, pero no suficiente para conocerse los tiempos actuales. Aquel objeto que Marx enfocó, cuyas determinaciones esenciales él reprodujo idealmente, hoy está cambiando. Es en ese sentido que El capital, como crítica de la economía política, es inacabable, éste sólo se agota cuando su objeto real se agote (2002).

Este es también el llamado de Konder, quien sostiene que: 


\section{CARLOS MONTAÑo}

El futuro de la filosofía de la praxis [remitiendo a la denominación gramsciana para «marxismo»] dependerá, con certeza, tanto de su capacidad de auto-renovación teórica como de la eficacia de su presencia en la acción política (...) Ella no tiene ninguna chance de sobrevivir refugiada en universidades o en institutos científicos; y tampoco tiene ninguna posibilidad de resistir a la autodisolución si renuncia a la rigurosidad teórica (1992:132-133).

Lo anterior supone que el movimiento de la realidad (su proceso de superación dialéctica, en sus continuidades y rupturas) debe ser acompañado por el movimiento del pensamiento (en un proceso de superación dialéctica del pensamiento marxista, también en sus continuidades y rupturas). La vitalidad del marxismo radica, entonces, en acompañar ese movimiento de la realidad, apropiándose de las nuevas determinaciones de la realidad en constante transformación.

En la sección previa tratamos cómo, frente a las continuidades y rupturas del capitalismo actual (el movimiento dialéctico del capitalismo), ha habido constantes esfuerzos del marxismo por apropiarse de las diversas nuevas determinaciones de la realidad, fieles al método de Marx y sus fundamentos (el movimiento dialéctico del «marxismo ortodoxo»). O sea, cómo la «dialéctica del capitalismo» (o el capitalismo en movimiento) ha sido apropiado teóricamente por la «dialéctica del marxismo ortodoxo» (o el pensamiento marxista en movimiento): el segundo (el movimiento del pensamiento, la dialéctica marxista) ha acompañado el proceso del primero (el movimiento de la realidad, la dialéctica de la realidad).

Así, como observa Hobsbawm, «la historia del marxismo no puede ser considerada como algo acabado, ya que el marxismo es una estructura del pensamiento aún vital» y constata que efectivamente «su continuidad 
fue sustancialmente ininterrumpida desde el tiempo de Marx y Engels» (1987:13) —en su Historia del marxismo él presenta la riqueza, la variedad y la actualidad a lo largo de la historia del pensamiento marxista.

La vitalidad, la vigencia, la actualidad del marxismo, radican entonces en su capacidad de constantemente remitirse a la realidad, desvelando (teóricamente) y actuando (políticamente). Y esa vitalidad y actualidad pasan por la presencia viva de los siguientes aspectos en el pensamiento marxista ortodoxo.

En primer lugar, por su capacidad de crítica (sobre la realidad y sobre los discursos no marxistas) y de autocrítica (de su propia elaboración teórica y de su acción política). Lukács, en entrevista a Leandro Konder, ya había expuesto la necesidad de una autocrítica del marxismo (Lukács, en Pinassi y Lessa, 2002:125 y ss.). Sin embargo, el marxismo en proceso de autocrítica y de constante renovación no debe derivar en el abandono de sus fundamentos, de su historia: se trata de la autocrítica de un marxismo «impenitente», en la feliz caracterización de Netto (2004).

En segundo lugar, su actualidad pasa por, como afirmara el propio Marx, «dudar de todo» (en Konder, 2003:83) cuando se explora la realidad y las elaboraciones teóricas.

Un tercer aspecto es la necesaria fidelidad con el método (materialista histórico y dialéctico) que, en la medida en que se apropia del bagaje teórico, busca captar el movimiento de la realidad, su estructura y sus fenómenos y particularidades. Para ello precisa, en una visión de totalidad, tratar las categorías fundantes de la realidad — de las ya abordadas por Marx y por los «clásicos» del marxismo, desde que éstas permanezcan reales, y de aquellas no tratadas por ellos, cuando se presenten como nuevas determinaciones de la realidad concreta. 


\section{CARLOS MONTAÑO}

Por otro lado, el vigor del pensamiento marxista pasa por siempre sustentarse en la «indignación» (Marx, 2005:147), como el sentimiento que funda y agudiza su interés (y sus valores) en la comprensión de la realidad para su transformación.

Finalmente, la vitalidad y actualidad del marxismo ortodoxo se sustenta en el ineliminable principio que funda la búsqueda del conocimiento teórico radical sobre los fundamentos de la realidad social-histórica, para orientar la práctica política. Estas son cuestiones vitales para la actualidad y vigencia del marxismo... y la vitalidad del marxismo es fundamental para la vitalidad del proyecto revolucionario que apunta a la emancipación humana.

\section{Referencias}

Amin, Samir y François Houtart (orgs.) (2003), Fórum Mundial das Alternativas.

Mundialização das Resistências. O Estado das lutas 2003, São Paulo, Cortez. Anderson, Perry (1985), A crise da crise do marxismo, São Paulo, Brasiliense.

Antunes, Ricardo (1999), Os sentidos do trabalho. Ensaio sobre a afirmação e a negação do trabalho, São Paulo, Boitempo.

Arrighi, Giovanni (1996), O longo Século XX. Dinheiro, poder e as origens de nosso tempo, Rio de Janeiro/São Paulo, Contraponto/Universidad Estadual Paulista.

Baran, Paul (1986), A Economia Política do Desenvolvimento, São Paulo, Nova Cultural.

Bensaïd, Daniel (2011), Marx ha vuelto, Buenos Aires, Edhasa. 
Borón, Atílio (2002), Império \& Imperialismo. Uma leitura crítica de Michel Hardt e Antonio Negri, Buenos Aires, Clacso.

Borón, Atílio et al. (orgs.) (2007), A teoria marxista hoje. Problemas e perspectivas, São Paulo, Expressão Popular.

Braverman, Harry (1987), Trabalho e Capital Monopolista. A degradação do trabalho no século XX, Rio de Janeiro, Guanabara.

Chesnais, François (1996), A mundialização do capital, São Paulo, Xamã.

Cueva, Agustín (1990), El desarrollo del capitalismo en América Latina, México, Siglo XXI.

Dos Santos, Theotonio (1972) Dependencia y Cambio Social, Santiago-Chile, do CESO.

Engels, Friedrich (1979), A dialética da natureza, Rio de Janeiro, Paz e Terra, en https://www.marxists.org/espanol/m-e/1880s/dianatura/index.htm (1882), «Engels to Eduard Bernstein in Zurich», Marxist Internet Archive, en https://marxists.catbull.com/archive/marx/works/1882/letters/82_11 _02.htm

(s/f), «Carta a Joseph Bloch», en https://www.marxists.org/espanol/ m-e/cartas/e21-9-90.htm

Fernández Buey, Francisco (2009), Marx (sem ismos), Rio de Janeiro, Universidad Federal do Rio de Janeiro.

Fontes, Virginia (2010), O Brasil e o capital-imperialismo. Teoria e história, Rio de Janeiro, Universidad Federal do Rio de Janeiro.

Gunder Frank, André (1983), Reflexões sobre a crise econômica mundial, São Paulo, Zahar.

Gramsci, Antonio (2000), Cadernos do Cárcere, volumen 3, Rio de Janeiro, Civilização Brasileira.

Harvey, David (1993), A condição pós-moderna, São Paulo, Edições Loyola. 


\section{CARLOS MONTAÑo}

(2004), O novo Imperialismo, São Paulo, Edições Loyola. (2005), O Neoliberalismo. História e implicações, São Paulo, Edições Loyola.

Hobsbawm, Eric (1987), História do Marxismo. O Marxismo no tempo de Marx; volumen 1, Rio de Janeiro, Paz e Terra.

(1995), Era dos extremos. O breve século XX, 1914-1991, São Paulo, Companhia das Letras.

Kausty, Karl (2002), As três fontes do marxismo, São Paulo, Centauro, en https:// www.marxists.org/espanol/kautsky/1907/lastresfuentesmarxismo-kautsky -1907.pdf

Konder, Leandro (1992), O futuro da Filosofia da Práxis. O pensamento de Marx no século XXI, Rio de Janeiro, Paz e Terra. (1999), Marx. Vida \& Obra, São Paulo, Paz e Terra. (2003), O que é dialética, São Paulo, Brasiliense.

Lenin, Vladímir Ilich (1977), O esquerdismo. Doença infantil do comunismo, Lisboa, Estampa. (1979), O Imperialismo: fase superior do capitalismo, São Paulo, Global. (1983), As três fontes e as três partes constitutivas do marxismo, São Paulo, Global, en http://www.marx2mao.com/M2M(SP)/Lenin(SP)/CPM13s.html (1989), Obras escolhidas, tomo 6, Lisboa/Moscou, Avante/Progresso. (2011), Cadernos sobre a dialética de Hegel, Rio de Janeiro, Universidad Federal do Rio de Janeiro.

Lojkine, Jean (1997), O Estado capitalista e a Questão Urbana, São Paulo, Martins Fontes.

Losurdo, Domenico (2004), Democracia ou bonapartismo, Rio de Janeiro, Universidad Federal do Rio de Janeiro/Universidad Estatal Paulista. 
Lukács, György (1974), História e consciência de classe. Estudos de dialética marxista, Porto, Publicações Escorpião, en https://www.marxists.org/espanol/ lukacs/1923/hcc.pdf

(2007), «As bases ontológicas do pensamento e da atividade do homem», en O jovem Marx e outros escritos de filosofia, Rio de Janeiro, Universidad Federal do Rio de Janeiro, en https://www.google.com/url?sa=t\& $\mathrm{rct}=\mathrm{j} \& \mathrm{q}=\&$ esrc $=\mathrm{s} \&$ source $=$ web $\& \mathrm{~cd}=1 \& \mathrm{cad}=\mathrm{rja} \& \mathrm{uact}=8 \& \mathrm{ved}=0 \mathrm{ahUKEwi}$ 80vzF7KTbAhWDiJAKHbrOAkcQFggrMAA\&url=https\%3A\%2F\%2Fomegal fa.es\%2Fdownloadfile.php\%3Ffile\%3Dlibros\%2Ffundamentos.ontologicos. pdf\&usg=AOvVawlVSCB4MMZohht5j--PSMhx (2008), Socialismo e democratização. Escritos políticos 1956-1971, Rio de Janeiro, Universidad Federal do Rio de Janeiro. (2010), Marxismo e teoria da literatura, São Paulo, Expressão Popular. (2012), Para uma ontologia do Ser Social I, São Paulo, Boitempo.

Luxemburgo, Rosa (1985), A Acumulação de Capital, São Paulo, Nova Cultural. Mandel, Ernest (1980), La crisis. 1974-1980, México, Era. (1982) O Capitalismo Tardio, São Paulo, Abril Cultural.

Mariátegui, José Carlos (1999), 7 ensayos de interpretación de la realidad peruana, Lima, Amauta.

Marini, Ruy Mauro (1977), Dialéctica de la Dependencia, México, Era.

Marx, Karl (1977), Contribuição à Crítica da Economia Política, São Paulo, Martins Fontes.

(1980 e 1985), O Capital (Crítica da Economia Política), Livros 1 e 3, Rio de Janeiro, Civilização Brasileira. (1985a), Formações Econômicas Pré-capitalistas, Rio de Janeiro, Paz e Terra. (2005), Crítica da Filosofia do Direito de Hegel, São Paulo, Boitempo. 


\section{CARLOS MONTAÑO}

(2011), Grundrisse, São Paulo, Boitempo.

Marx, Karl y Friedrich Engels (1975), Textos 1, São Paulo, Edições Sociais.

(1987), Correspondencia, Buenos Aires, Cartago.

(1998), Manifesto do Partido Comunista, São Paulo, Cortez, en https://

www.marxists.org/espanol/m-e/1840s/48-manif.htm

Mészáros, István (2002), Para além do capital, São Paulo, Boitempo.

(2009), A crise estrutural do capital, São Paulo, Boitempo.

Montaño, Carlos (1998), La naturaleza del servicio social. Un ensayo sobre su génesis, su «especificidad» y su reproducción, São Paulo, Cortez.

(2013), «Breves anotações sobre o método e a teoria em Marx», en Carlos

Montaño y R. Lustosa (orgs.), Conhecimento e sociedade. Ensaios marxistas,

São Paulo, Outras Expressões.

Netto, José Paulo (1983), Georg Lukács. O guerreiro sem repouso, São Paulo, Brasiliense.

(1990), O que é Marxismo, São Paulo, Brasiliense.

(2002), O Método em Marx, Maceió, UFAL, en http://www.ess.ufrj.br/ nepem/sites/www.ess.ufrj.br.movimentossociais/files/O-METODO-EMMARX.pdf

(2004), Marxismo Impenitente. Contribuição à história das ideias marxistas, São Paulo, Cortez.

O'Connor, James (1977), USA: a crise do Estado capitalista, São Paulo, Rio de Janeiro.

Petras, James (1999), Neoliberalismo: América Latina, Estados Unidos e Europa. Blumenau, Universidade Regional de Blumenau.

Petras, James y Henry Veltmeyer (2004), Las dos caras del imperialismo. Vasallos y guerreros, Argentina/México, Lumen. 
(2005), Movimientos Sociales y poder estatal. Argentina, Brasil, Bolivia, Ecuador, Argentina/México, Lumen.

Pinassi, M. Orlanda y Sérgio Lessa (orgs.) (2002), Lukács e a atualidade do marxismo, São Paulo, Boitempo.

Santos, Boaventura de Souza (1997), Pela mão de Alice. O social e o político na pós-modernidade, São Paulo, Cortez.

Sweezy, Paul (1986), Teoria do Desenvolvimento Capitalista, São Paulo, Nova Cultural.

Teixeira, Francisco y Celso Frederico (2008), Marx no século XXI, São Paulo, Cortez.

Trotsky, Leon (2007), A História da Revolução Russa, São Paulo, Sundermann.

Wood, Ellen (2006), Democracia contra capitalismo. A renovação do materialismo histórico, São Paulo, Boitempo.

Wright Mills, Charles (1968), Os Marxistas, Rio de Janeiro, Zahar. 